\title{
Comparative histopathological analysis of sporadic pediatric papillary thyroid carcinoma from Japan and Ukraine
}

\author{
Tetiana I. Bogdanova ${ }^{1), 2)}$ *, Vladimir A. Saenko ${ }^{1)}$ *, Mitsuyoshi Hirokawa ${ }^{3)}$, Masahiro Ito ${ }^{4)}$, \\ Liudmyla Yu. Zurnadzhy ${ }^{2)}$, Toshitetsu Hayashi ${ }^{3)}$, Tatiana I. Rogounovitch ${ }^{1)}$, Akira Miyauchi ${ }^{3)}$, \\ Mykola D. Tronko ${ }^{2)}$ and Shunichi Yamashita ${ }^{1)}$ \\ 1) Atomic Bomb Disease Institute, Nagasaki University, Nagasaki 852-8523, Japan \\ 2) State Institution "V.P.Komisarenko Institute of Endocrinology and Metabolism of NAMS of Ukraine", 69 Vyshgorodska str., \\ 04114 Kyiv, Ukraine \\ 3) Kuma Hospital, Kobe 650-0011, Japan \\ 4) Nagasaki Medical Center, Omura 856-8562, Japan
}

\begin{abstract}
This study set out to compare structural and invasive characteristics of sporadic papillary thyroid carcinoma (PTC) in age-matched groups of children and adolescents of Japan and Ukraine to provide detailed histopathological analysis of tumors from different geographical areas with different iodine intake. A total of 348 (160 Japanese and 188 Ukrainian) PTCs from patients without radiation history were analyzed initially as a combined pediatric group and then subdivided into childhood (aged $\leq 14$ years) and adolescent (aged from 15 to $\leq 18$ years) age series. On multivariate comparison, the Japanese pediatric PTC was characterized by a higher sex ratio $(p=1.504 \mathrm{E}-4)$, and a higher frequency of microcarcinoma $(p=0.039)$, papillary dominant growth pattern $(p=0.024)$, focal oxyphilic cell metaplasia $(p=7.644 \mathrm{E}-6)$, intrathyroid spread $(p=0.010)$, lymphatic/vascular invasion $(p=0.01)$ and regional lymph node metastases $(p=3.540 \mathrm{E}-6)$. In the Ukrainian group, multifocal $(p=0.004)$ and non-encapsulated tumors with the solid-trabecular growth pattern $(p=0.05)$ were more frequent. Childhood Japanese PTCs differed from Ukrainian PTCs by more pronounced invasive properties such as lymphatic/vascular invasion and nodal disease, but did not differ by the dominant growth pattern. In adolescents, the differences were detected not only for lymph node metastases, but also for a higher frequency of the papillary dominant pattern in Japanese PTC. Overall, significantly higher frequencies of oxyphilic cell metaplasia and more pronounced invasive features observed in the Japanese PTC in both age-matched series represent the major differences between the tumors from two geographical areas.
\end{abstract}

Key words: Pediatric papillary thyroid carcinoma, Pathology, Japan, Ukraine, Sporadic thyroid cancer

DIFFERENTIATED THYROID CANCER is rare at young age and accounts for $0.5-3 \%$ of all pediatric malignancies [1]. In Japan, according to the Center for Cancer Control and Information Services, National Cancer Center, incidence of thyroid cancer in children $0-19$ years old varied age-dependently from 0 to 1.4 per 100,000 during 2002-2012 [2]. In Ukraine, incidence of sporadic thyroid cancer in children aged 4-18 years was from 0.1 to 2.4 per 100,000 during 20062014 [3].

Submitted Mar. 28, 2017; Accepted Jul. 6, 2017 as EJ17-0134 Released online in J-STAGE as advance publication Aug. 10, 2017 Correspondence to: Vladimir A. Saenko, Department of Radiation Molecular Epidemiology, Atomic Bomb Disease Institute, Nagasaki University 1-12-4 Sakamoto, Nagasaki 852-8523, Japan. E-mail: saenko@nagasaki-u.ac.jp

* Equal contribution

(C) The Japan Endocrine Society
Our previous work reported differences in tumor structure and invasive properties between Japanese and Ukrainian sporadic papillary thyroid carcinoma (PTC) in adult patients [4]. The Japanese PTC was characterized by a higher frequency of papillary architecture and invasive features such as extrathyroidal extension and regional lymph node metastases. Ukrainian PTC displayed the higher frequency of solid growth pattern and of oxyphilic cell metaplasia. These differences were ascribed to distinct geographical origin with corresponding country-specific diet and different iodine consumption, and to different genetic backgrounds.

By contrast, single papers on the comparative analysis of Japanese and Belarussian-Ukrainian pediatric PTC pointed at the higher frequency of solid structural component and more frequent invasive 
features in the latter. The higher invasiveness of Belarussian-Ukrainian PTC is at variance with adult PTC. Importantly, however, these comparisons were made between the tumors developing after radiation exposure from the Chernobyl fallouts in Belarus and Ukraine, and sporadic PTC from Japan [5, 6], which are etiologically different.

The aim of this study was to answer whether sporadic pediatric PTC from Ukraine displays the differences in tumor architectonics and invasiveness similar to those seen in sporadic adult tumors or in radiationrelated pediatric ones, as compared to sporadic PTC in age-matched group of patients from Japan.

\section{Materials and Methods}

\section{Patients}

The total number of cases of pediatric PTC was 348, including 160 patients operated at Kuma Hospital (Kobe city, Japan), which is one of the main centers of endocrine surgery in the country, and 188 operated at State Institution "V.P.Komisarenko Institute of Endocrinology and Metabolism of the National Academy of Medical Sciences of Ukraine" (Kiev, Ukraine), a leading research center for study and treatment of thyroid diseases in Ukraine. None of patients had radiation history. All patients from Japan lived in the Prefectures other than Fukushima, and their tumors were not detected during ultrasound screening. Patients from Ukraine were born after the Chernobyl accident since 1987 when radioactive iodine had decomposed and resided in the regions of Ukraine distant from Chernobyl. For each country, all PTCs were firstly analyzed as a whole pediatric group and then subdivided into two age series: children aged $\leq 14$ (42 Japanese cases and 98 Ukrainian) and adolescents aged from 15 to $\leq 18$ years (118 and 90 cases, respectively) in order to perform a comparison with previously published data $[5,6]$.

\section{Histopathology}

Histopathological examination of hematoxylin/ eosin stained paraffin sections was initially performed at the centers of origin by two experienced pathologists (MH and TH at Kuma Hospital, and TB and LZ at the Institute of Endocrinology and Metabolism). The pathological classification was based on the World Health Organization definitions [7].

Joint protocol was developed for the analysis of morphological characteristics by TB, MH, MI and VS. Tumor size, as a continuous variable, was defined by the largest diameter on macroscopic pathological description. Tumor architecture determined by the dominant histological pattern (papillary, follicular or solid-trabecular when corresponding structure represented $>50 \%$ of tumor section) and invasive characteristics were used as categorical data. Only marked intrathyroid spread over the lobe/lobes was considered positive, including the diffuse-sclerosing variant-like one. Lymphatic and blood vessel invasion were combined into one parameter, the lymphatic/vascular invasion. Extrathyroidal extension included not only tumor invasion to the muscle, but also minimal protrusion beyond the thyroid capsule to adjacent adipose and connective tissues. Distant metastases to the lung were determined by radioactive iodine scans performed following thyroidectomy. No distant metastases to the bone, the brain or other sites were detected. Tumor staging was according to the 7th edition of TNM classification system [8], which assigns minimal extrathyroidal extension pT3 category $[4,9]$.

Oxyphilic (oncocytic/Hurtle) cell metaplasia was evaluated as absent, focal or severe, including oxyphilic cell PTC. Concomitant nodular or diffuse thyroid pathology was also considered as categorical variables. The analysis of rarer histological subtypes between the two countries was done separately.

TB and MI re-reviewed histological specimens and entered all data digitally into spreadsheets for subsequent statistical analysis.

\section{Statistical analysis}

Fisher's exact test for categorical data and MannWhitney or Kruskal-Wallis tests for quantitative measurements were used in univariate analyses. Multivariate logistic regression analyses, either binary or multinomial, were adjusted for age at surgery and sex. Calculations were performed using IBM SPSS Statistics Version 21 software (International Business Machines Corp., Armonk, NY, USA); $p$-values were 2-sided and considered significant if $p \leq 0.05$.

Our previous studies showed that invasive properties of PTC significantly differed between fully encapsulated and non-encapsulated/partially encapsulated tumors [10]. Therefore, separate analyses were performed for all, fully encapsulated and non-encapsulated tumors. 


\section{Results}

\section{Pediatric Japanese and Ukrainian sporadic PTC}

Comparative analysis of pediatric sporadic PTC (all patients) from the two countries showed significantly younger patients' age at surgery in Ukrainian series (Table $1 ; 14.1 \pm 3.2 v s .16 .0 \pm 2.8$ years, $p=2.150 \mathrm{E}-10$ ). In both groups female patients were prevailing, but the relative proportion of male patients was markedly higher in Ukrainian than in Japanese group (F:M ratio 2.6:1 vs. 7.9:1, respectively, $p=1.504 \mathrm{E}-4)$, as was the frequency of fully encapsulated PTC $(\mathrm{OR}=4.626$, $p=0.001)$. There was no difference in mean size of tumors from the two countries, although in the Ukrainian group the frequency of non-encapsulated micro-PTC measuring $\leq 10 \mathrm{~mm}$ was nearly two times lower as compared to the Japanese $(9.0 \% v s .18 .7 \%, p=$ 0.039 on univariate analysis, Supplementary Table 1).

Ukrainian PTC in comparison with the Japanese tumors also displayed statistically significant differences both in the dominant tumor growth pattern and invasive properties on multivariate analysis adjusted for sex and age. The lower frequency of dominant papillary growth pattern $(\mathrm{OR}=0.519, p=0.024)$, focal oxyphilic cell metaplasia (OR=0.191, $p=7.644 \mathrm{E}-6)$, intrathyroid spread $(\mathrm{OR}=0.509, p=0.010)$, lymphatic/ vascular invasion $(\mathrm{OR}=0.517, p=0.010)$ and regional lymph node metastases $(\mathrm{OR}=0.290, p=3.540 \mathrm{E}-6)$ was observed (Table 1). On the other hand, Ukrainian PTCs displayed a higher frequency of tumors with the dominant solid pattern $(\mathrm{OR}=1.776, p=0.050$ for non-encapsulated tumors, Supplementary Table 1) and multifocal growth $(\mathrm{OR}=5.300, p=0.004)$. All these associations were mostly seen for non-encapsulated PTCs, the frequency of which was significantly higher in Ukrainian cases $(\mathrm{OR}=4.626, p=0.001)$.

When PTCs with the dominant papillary growth pattern were analyzed (Supplementary Table 2), a lower frequency of tumors with important indicators of tumor invasiveness such as lymphatic/vascular invasion $(\mathrm{OR}=0.519, p=0.044)$ and regional lymph node metastases $(\mathrm{OR}=0.336, p=0.005)$, as well as with focal oxyphilic cell metaplasia $(\mathrm{OR}=0.204, p=4.020 \mathrm{E}-6)$ was observed in the Ukrainian group. PTCs with the solid-trabecular architecture displayed minor differences in tumor invasiveness (Supplementary Table 3),

Table 1 Comparative characteristics of the Japanese and Ukrainian pediatric sporadic papillary thyroid carcinoma (all patients aged $\leq 18$ years at surgery)

\begin{tabular}{|c|c|c|c|c|c|c|c|}
\hline & \multicolumn{2}{|c|}{ Japan $(n=160)$} & \multicolumn{2}{|c|}{ Ukraine $(n=188)$} & \multirow[b]{2}{*}{$p$-value (uni) } & \multirow[b]{2}{*}{ OR $(95 \% \mathrm{CI})^{2}$} & \multirow[b]{2}{*}{$\begin{array}{l}p \text {-value } \\
\text { (multi) }^{3}\end{array}$} \\
\hline & $\begin{array}{l}\text { Number } \\
\text { or value }\end{array}$ & $\%$ or $\mathrm{SD}^{1}$ & $\begin{array}{l}\text { Number } \\
\text { or value }\end{array}$ & $\%$ or $\mathrm{SD}$ & & & \\
\hline \multicolumn{8}{|c|}{ Baseline characteristics and tumor histopathology } \\
\hline Age (mean, years) & 16.0 & 2.8 & 14.1 & 3.2 & 2.150E-10 & & \\
\hline $\operatorname{Sex}(F / M)$ & $142 / 18$ & $\mathrm{~F}: \mathrm{M}=7.9: 1$ & $136 / 52$ & $\mathrm{~F}: \mathrm{M}=2.6: 1$ & $1.504 \mathrm{E}-4$ & & \\
\hline Tumor capsule & 6 & 3.7 & 31 & 16.5 & 8.995E-5 & $4.626(1.826-11.719)$ & 0.001 \\
\hline Size (mean, mm) & 23.4 & 14.3 & 24.1 & 14.3 & 0.706 & & \\
\hline Size $\leq 10 \mathrm{~mm}$ & 30 & 18.7 & 23 & 12.2 & 0.101 & $0.686(0.367-1.282)$ & 0.237 \\
\hline \multicolumn{8}{|l|}{ Dominant pattern } \\
\hline Papillary & 99 & 61.9 & 88 & 46.8 & 0.005 & $0.519(0.375-0.934)$ & 0.024 \\
\hline Follicular & 34 & 21.2 & 49 & 26.1 & 0.315 & $1.255(0.736-2.141)$ & 0.405 \\
\hline Solid-trabecular & 27 & 16.9 & 51 & 27.1 & 0.028 & $1.683(0.967-2.930)$ & 0.066 \\
\hline Oxyphilic changes & 84 & 52.5 & 48 & 25.5 & 2.903E-7 & $0.334(0.207-0.540)$ & $7.606 \mathrm{E}-6$ \\
\hline Concomitant nodular pathology & 15 & 9.4 & 18 & 9.6 & 1.000 & $1.171(0.543-2.523)$ & 0.687 \\
\hline Concomitant diffuse pathology & 61 & 38.1 & 55 & 29.3 & 0.088 & $0.869(0.539-1.401)$ & 0.565 \\
\hline \multicolumn{8}{|l|}{ Tumor invasiveness } \\
\hline Intrathyroid spread & 53 & 33.1 & 43 & 22.9 & 0.041 & $0.509(0.305-0.851)$ & 0.010 \\
\hline Extrathyroidal extension (pT3) & 77 & 48.1 & 96 & 51.1 & 0.593 & $0.870(0.551-1.373)$ & 0.550 \\
\hline Multifocality (pTm) & 4 & 2.5 & 22 & 11.7 & 0.001 & $5.300(1.728-16.257)$ & 0.004 \\
\hline Lymphatic/vascular invasion & 122 & 76.3 & 123 & 65.4 & 0.034 & $0.517(0.313-0.865)$ & 0.010 \\
\hline Lymph node metastases (pN1) & 129 & 80.6 & 110 & 58.5 & $9.448 E-6$ & $0.290(0.171-0.489)$ & 3.540E-6 \\
\hline Distant metastases (M1) & 14 & 8.8 & 20 & 10.6 & 0.591 & $0.671(0.299-1.507)$ & 0.334 \\
\hline
\end{tabular}


which was relatively high for both countries, except for the lower frequency of lymph node metastases in the Ukrainian group $(\mathrm{OR}=0.278, p=0.035)$.

The subdivision of PTCs by one of the three dominant structural components (papillary, follicular or solid-trabecular) demonstrated that in the Japanese group (Supplementary Table 4), focal oxyphilic cell metaplasia specifically associated with the papillary tumor structure $(p<0.03$ for comparisons with all other growth patterns). The frequency of concomitant chronic thyroiditis $(\mathrm{OR}=2.956, p=0.031)$ and of lymph node metastases $(\mathrm{OR}=2.656, p=0.042)$ was higher for the tumors with papillary growth than for those with follicular pattern. At the same time, the frequency of extrathyroidal extension of tumors with papillary growth pattern was lower than of PTCs with solid-trabecular structure $(\mathrm{OR}=0.349, p=0.024)$.

In the Ukrainian group (Supplementary Table 5), dominant follicular growth pattern was associated with the presence of tumor capsule $(p<0.01$ for all comparisons) and with the lower chance of concomitant chronic thyroiditis ( $p<0.05$ for all comparisons). Tumors with follicular growth pattern also displayed the lower frequency of severe oxyphilic cell metaplasia
$(\mathrm{OR}=0.060, p=0.009)$ and of extrathyroidal extension $(\mathrm{OR}=0.423, p=0.041)$ than those with dominant solid-trabecular structure, and of lymphatic/vascular invasion $(\mathrm{OR}=0.288, p=0.035)$ as compared with PTCs with the papillary growth pattern. Solid-trabecular structures were associated with the higher frequency of severe oxyphilic cell metaplasia $(\mathrm{OR}=7.614, p=0.001)$ and, similarly to the Japanese group, of extrathyroidal extension $(\mathrm{OR}=2.297, p=0.047)$.

\section{Childhood Japanese and Ukrainian sporadic PTC}

The results of analysis are presented in Table 2. The relative proportion of male patients was higher in the Ukrainian than in Japanese series, but only for non-encapsulated tumors the ratio was borderline statistically significant (F:M ratio 2.0:1 vs. 5.5:1, respectively, $p=0.050$, Supplementary Table 6 ). There were no differences in the mean size of tumors or in the frequency of micro-PTC, as well as in the frequency of each of three dominant components (Table 2).

In childhood Ukrainian PTC, similarly to the combined pediatric group, the lower frequency of focal oxyphilic cell metaplasia $(\mathrm{OR}=0.263, p=0.003)$, intrathyroid spread $(\mathrm{OR}=0.435, p=0.040)$, lymphatic/

Table 2 Comparative characteristics of the Japanese and Ukrainian sporadic papillary thyroid carcinoma in children aged $\leq 14$ years at surgery

\begin{tabular}{|c|c|c|c|c|c|c|c|}
\hline & \multicolumn{2}{|c|}{ Japan $(n=42)$} & \multicolumn{2}{|c|}{ Ukraine $(n=98)$} & \multirow[b]{2}{*}{$p$-value (uni) } & \multirow[b]{2}{*}{ OR $(95 \% \mathrm{CI})^{2}$} & \multirow[b]{2}{*}{$\begin{array}{l}p \text {-value } \\
(\text { multi) }\end{array}$} \\
\hline & $\begin{array}{l}\text { Number } \\
\text { or value }\end{array}$ & $\%$ or $\mathrm{SD}^{1}$ & $\begin{array}{l}\text { Number } \\
\text { or value }\end{array}$ & $\%$ or $\mathrm{SD}$ & & & \\
\hline \multicolumn{8}{|c|}{ Baseline characteristics and tumor histopathology } \\
\hline Age (mean, years) & 12.1 & 2.3 & 11.7 & 2.6 & 0.418 & & \\
\hline $\operatorname{Sex}(F / M)$ & $36 / 6$ & $\mathrm{~F}: \mathrm{M}=6.0: 1$ & $68 / 30$ & $\mathrm{~F}: \mathrm{M}=2.3: 1$ & 0.057 & & \\
\hline Tumor capsule & 3 & 7.1 & 19 & 19.4 & 0.079 & $3.495(0.961-12.709)$ & 0.057 \\
\hline Size (mean, mm) & 24.0 & 14.7 & 24.2 & 14.2 & 0.095 & & \\
\hline Size $\leq 10 \mathrm{~mm}$ & 3 & 7.1 & 11 & 11.2 & 0.554 & $1.570(0.403-6.124)$ & 0.516 \\
\hline \multicolumn{8}{|l|}{ Dominant pattern } \\
\hline Papillary & 22 & 52.4 & 43 & 43.9 & 0.363 & $0.686(0.327-1.441)$ & 0.320 \\
\hline Follicular & 12 & 28.6 & 25 & 25.5 & 0.835 & $0.923(0.399-2.138)$ & 0.857 \\
\hline Solid-trabecular & 8 & 19.0 & 30 & 30.6 & 0.214 & $1.813(0.739-4.447)$ & 0.194 \\
\hline Oxyphilic changes & 21 & 50.0 & 21 & 21.4 & 0.001 & $0.265(0.119-0.590)$ & 0.001 \\
\hline Concomitant nodular pathology & 3 & 7.1 & 9 & 9.2 & 1.000 & $1.230(0.309-4.905)$ & 0.769 \\
\hline Concomitant diffuse pathology & 14 & 33.3 & 27 & 27.6 & 0.545 & $0.910(0.404-2.052)$ & 0.820 \\
\hline \multicolumn{8}{|l|}{ Tumor invasiveness } \\
\hline Intrathyroid spread & 17 & 40.5 & 23 & 23.5 & 0.065 & $0.435(0.197-0.961)$ & 0.040 \\
\hline Extrathyroidal extension (pT3) & 25 & 59.5 & 58 & 59.2 & 1.000 & $0.919(0.429-1.966)$ & 0.827 \\
\hline Multifocality (pTm) & 0 & 0.0 & 10 & 10.2 & 0.033 & $\mathrm{ND}^{4}$ & ND \\
\hline Lymphatic/vascular invasion & 37 & 88.1 & 66 & 67.3 & 0.012 & $0.253(0.089-0.721)$ & 0.010 \\
\hline Lymph node metastases (pN1) & 35 & 83.3 & 63 & 64.3 & 0.027 & $0.342(0.136-0.861)$ & 0.023 \\
\hline Distant metastases (M1) & 7 & 16.7 & 15 & 15.3 & 0.806 & $0.766(0.274-2.140)$ & 0.611 \\
\hline
\end{tabular}


vascular invasion $(\mathrm{OR}=0.253, p=0.010)$ and regional lymph node metastases $(\mathrm{OR}=0.342, p=0.023)$ were observed. There were no multifocal tumors in Japanese patients in contrast to $10 \%$ in Ukrainian $(p=0.033)$. The frequency of distant metastases to the lung in patients from both countries was higher than in the combined group of children and adolescents ( $8-10 \% v s .15-16 \%$, respectively) but no statistically significant difference was observed between the two countries.

\section{Adolescent Japanese and Ukrainian sporadic PTC}

Ukrainian patients were markedly younger than Japanese (Table 3; $16.7 \pm 1.2$ vs. $17.4 \pm 1.1$ years, respectively, $p=1.381 \mathrm{E}-5)$. Similarly to the combined pediatric group, statistically significant difference was found for sex ratio (F:M ratio 3.1:1 vs. 8.8:1, $p=0.008$ ), and for the frequencies of fully encapsulated tumors $(\mathrm{OR}=5.658, p=0.012)$, small non-encapsulated PTC $(\mathrm{OR}=0.373, p=0.029)$, dominant papillary growth pattern $(\mathrm{OR}=0.537, p=0.042)$ and focal oxyphilic cell metaplasia $(\mathrm{OR}=0.288, p=0.001)$ in Ukrainian PTCs.

With regard to tumor invasiveness, significant difference was found only for the frequency of regional lymph node metastases, which was lower in the Ukrainian series $(\mathrm{OR}=0.252, p=4.906 \mathrm{E}-5)$. Multifocality was more frequent in the tumors from Ukraine $(\mathrm{OR}=3.988$, $p=0.025$ ), in line with the findings in childhood series and in the combined pediatric group.

All differences were confined to the non-encapsulated tumors (Supplementary Table 7).

\section{Age-dependent changes in tumor invasiveness}

In both countries, the age-related decline of tumor invasiveness was seen. In Japan (Supplementary Table 8 ), in non-encapsulated tumors there was a reduction in the frequencies of extrathyroidal extension $(\mathrm{OR}=0.471$, $p=0.050)$, lymphatic/vascular invasion $(\mathrm{OR}=0.210$, $p=0.015)$, and distant metastases $(\mathrm{OR}=0.306, p=0.039)$ in adolescents as compared to children. The decrease in tumor size and in the frequency of microcarcinoma was also observed ( $p=0.014$ and 0.043 , respectively). In Ukrainian cases (Supplementary Table 9), a reduction in the frequencies of extrathyroidal extension $(\mathrm{OR}=0.345, p=0.002)$, regional lymph node metastases $(\mathrm{OR}=0.490, p=0.043)$, and distant metastases $(\mathrm{OR}=0.306, p=0.031)$ were found for non-encapsulated tumors.

Table 3 Comparative characteristics of the Japanese and Ukrainian sporadic papillary thyroid carcinoma in adolescents aged from 15 to $\leq 18$ years at surgery

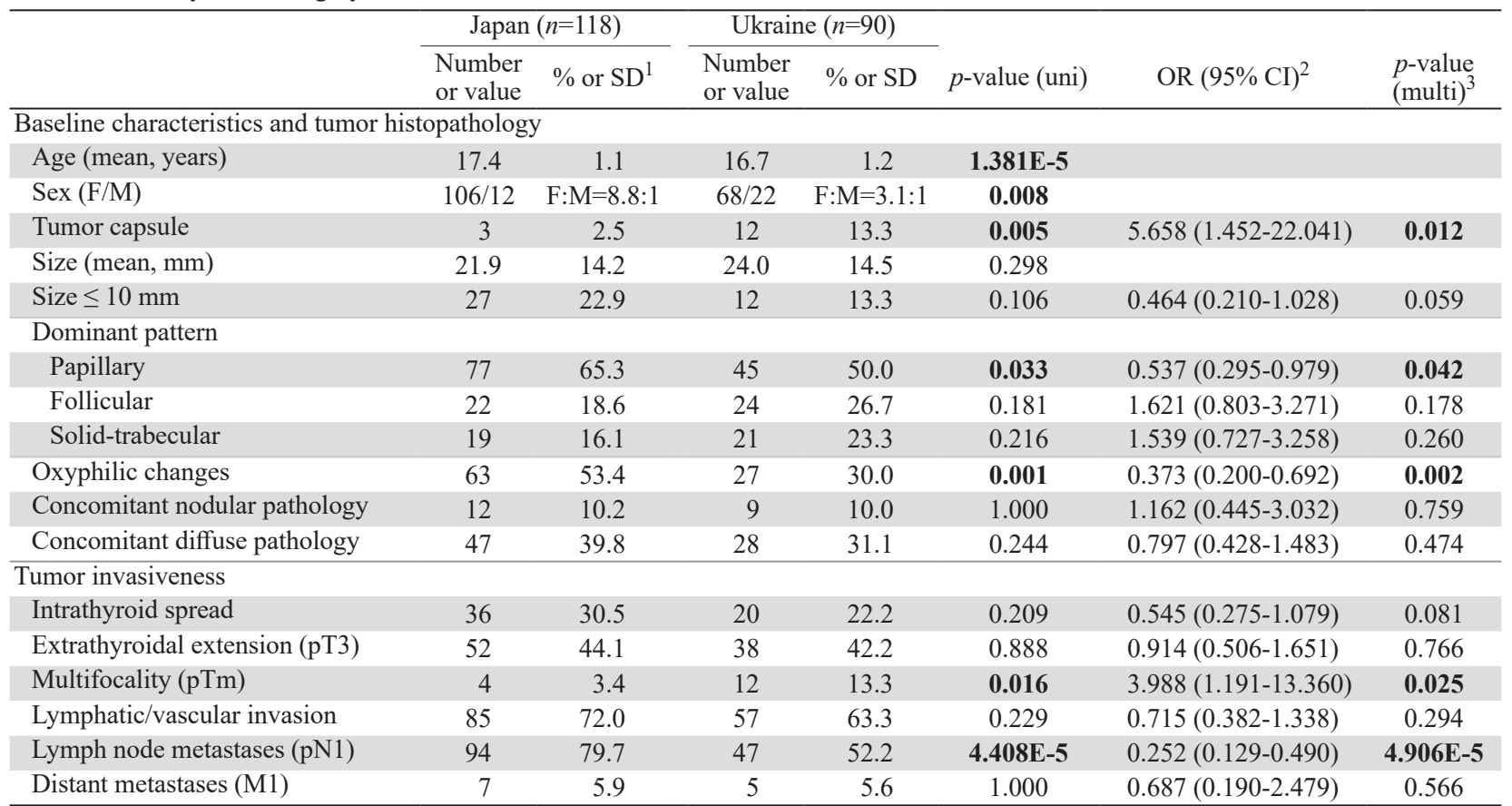

$1 \%$ for count data, SD for continuous numeric data. ${ }^{2}$ Corresponding parameters in the Japanese series served as a reference. ${ }^{3}$ Adjusted for age and sex. 


\section{Discussion}

Histopathological features of Japanese childhood PTC were described just in two studies, in which the comparative analyses of radiogenic post-Chernobyl PTC and sporadic Japanese PTC were performed [5, 6]. In both of these publications, differences between the groups from two countries were detected for tumor architecture and invasiveness. Japanese childhood PTC was characterized by the higher frequency of the papillary architecture and the lower frequency of extrathyroidal extension than post-Chernobyl radiogenic tumors. It should be noted that during the study by Williams et al. [6], a limited number of sporadic PTCs detected in children born after the Chernobyl accident was also included (23 cases from Belarus, Ukraine and Russia cumulatively), which showed no difference in characteristics from radiogenic childhood post-Chernobyl PTCs. Consequently, the Japanese childhood PTC demonstrated a higher frequency of tumors with the dominant papillary structure and a lower frequency of extrathyroidal extension not only in comparison with post-Chernobyl radiogenic carcinomas, but also with sporadic PTC in children of Belarus, Ukraine and Russia.

By contrast, recent studies in larger series of radiogenic and sporadic Ukrainian and Belarusian PTCs did find certain difference in the morphological and invasive characteristics of pediatric tumors of different etiology $[11,12]$. Therefore, in the present work we performed more detailed comparative histopathological analysis of Japanese and Ukrainian sporadic PTC in childhood and adolescent patients using a relatively large number of cases (160 and 188, respectively).

Our analysis, at variance to previous reports, demonstrated that childhood PTC showed no pronounced difference in the ratio of three main dominant growth pattern: papillary, follicular and solid-trabecular (see Table 2). On the other hand, a higher frequency of the papillary dominant growth pattern was observed in the Japanese adolescent PTC and in the combined pediatric group (see Tables 1,3), similarly to earlier reports $[5,6]$.

The frequency of PTC with the dominant solid growth pattern was somewhat higher in both childhood and adolescent Ukrainian than in Japanese group, but statistical significance was achieved only in the combined group of pediatric PTC (see Table 1). The reported earlier higher frequency of the solid component in childhood PTC from Ukraine, Belarus and Russia [6], and in PTC of adult patients from Ukraine without radiation history [4] was considered the major structural difference between Japanese and Ukrainian PTC. This difference has been proposed to be due to iodine deficiency in the areas around Chernobyl, including Ukraine. Less differentiated morphological features (solid-trabecular architecture) were associated with insufficient dietary iodine, whereas more differentiated tumor morphology (dominant papillary pattern) with adequate iodine intake. Iodine deficiency was thought to influence PTC morphology and tumor aggressiveness [6].

The present study did not confirm the above assumption regarding the difference in the architecture of Japanese and Ukrainian childhood PTC. One of the reasons for this may be that in the past, the Japanese pathologists used to classify thyroid tumors with an abundant solid component as poorly differentiated carcinomas. Consequently, such tumors might not have been previously included in the comparative analyses of PTC. Recently published data on the frequency of PTC with the dominant solid structure in Japanese patients aged $\leq 20$ years at surgery [13] demonstrate that it is not meaningfully or significantly different from that in our study (8/81 cases, $10 \%$ vs. $27 / 160$ cases, $16.9 \%$, respectively, $p=0.177$ ). Results obtained in this work taken together with those of the previous study of adult PTC patients [4] suggest that iodine deficiency in Ukraine may influence the frequency of PTC with the solid growth pattern in adults, but not in children or adolescents separately.

It is interesting to note that the absence of difference in tumor architecture in childhood patients (see Table 2 ) and the higher frequency of the dominant papillary growth pattern in adolescents of Japan $v s$. Ukraine (see Table 3) might be partly explained by the presence of $B R A F^{\mathrm{V} 600 \mathrm{E}}$ mutation in corresponding tumors, which is known to associate with the papillary tumor structure [14]. Reviewing two relatively recent molecular genetic analyses of Ukrainian [15] and Japanese [16] PTC, we found no statistically significant difference in the prevalence of this mutation between Ukrainian and Japanese sporadic childhood PTC $(2 / 8,25.0 \%$ vs. 3/9 $33.3 \%$, respectively; $p=1.000$ ). On the contrary, the difference was seen in adolescents $(4 / 16,25 \%$ in Ukraine and $18 / 24,75 \%$ in Japan, $p=0.003$ ) that corresponds well to the higher frequency of tumors with the papillary architecture in this age subgroup. This explanation should certainly be viewed with caution because of the small size of childhood sample; it requires replication in larger independent groups. 
The dominant growth pattern, discussed above, largely reflects the histological subtype/variant of PTC and/or indicates the prevalent structural component of tumors with mixed structure. Rarer PTC subtypes such as diffuse-sclerosing (DSV), Warthin-like (WLV) and tall cell (TCV) variants were identified in a small number of cases. DSV and WLV were observed in the Japanese group in 2 and 2 out of 160 cases $(1.3 \%$ and $1.3 \%$, respectively), and in 5 and 1 out of 188 Ukrainian cases $(2.7 \%$, and $0.5 \%$, respectively), not significantly different between the countries ( $p=0.459$ and $p=0.596$, respectively). DSV tumors were represented by the papillary or solid foci spreading to both lobes, and WLV by the dominant papillary growth pattern. TCV was detected only in the Japanese group in $5 / 160$ cases $(3.1 \%, \mathrm{OR}=13.334, p=0.020$ in comparison with the Ukrainian group by univariate analysis). TCV was represented by the dominant papillary growth pattern in 3 cases and by the solid-trabecular structure in 2 cases. Since the number of tumors of the rare PTC subtypes was small in both Japanese and Ukrainian series, they would unlikely have introduced significant bias in the comparative analysis of PTCs from the two countries.

In contrast to very modest difference in tumor architecture, a significantly higher frequency of the indicators of tumor invasiveness found concordantly in the Japanese pediatric (this study) and adult PTC [4] may suggest that iodine-rich diet could be a risk factor for higher morphological tumor aggressiveness in any age group. Noteworthy, the higher frequency of regional lymph node metastases in Japanese PTC was observed both in children and adolescents (see Tables 1-3), further attesting to the validity of a notion on a higher morphological aggressiveness of PTC in young Japanese patients.

Our results are also at variance with the previous report on the higher frequency of extrathyroidal extension in the Ukrainian-Belarusian-Russian childhood PTC as compared to tumors from Japan [6]. The prevalence of PTCs featuring extrathyroidal extension in the Japanese combined pediatric group in our study $(77 / 160,48.1 \%)$ nearly coincides with those in two studies of sporadic pediatric thyroid cancer from Japan: $63 / 142,44.4 \%$ ( $p=0.565$ for difference with our data) [17] and 32/80, 40.0\% $(p=0.272)$ [13]. We explain the discrepancy with the previous work [6] by a relatively small number of patients with sporadic PTC in it and also by the fact that radiogenic PTC after
Chernobyl apparently displays morphological features of tumor aggressiveness more frequently than sporadic tumors $[11,12]$.

In conclusion, our study demonstrated that childhood Japanese PTC differed from Ukrainian PTC by more pronounced invasive properties such as lymphatic/vascular invasion and nodal disease, but did not differ by the dominant growth pattern. In adolescents, the difference was detected not only for lymph node metastases, but also for a higher frequency of the papillary dominant pattern in Japanese PTC. Ukrainian PTC displayed more frequent multifocal tumor growth and less frequent oxyphilic cell changes. In the combined pediatric PTC, the higher frequency of tumor invasive features such as intrathyroid spread, lymphatic/vascular invasion and nodal disease, and of the dominant papillary growth pattern in the Japanese group were also confirmed. In addition, it was possible to detect a higher frequency of the solid dominant growth pattern and of multifocal growth, and the lower frequency of oxyphilic cell metaplasia in Ukrainian PTC. The results demonstrate the presence of considerable differences in clinicopathological characteristics of pediatric PTC from Japan and Ukraine, the geographic areas with very different dietary iodine intake.

\section{Acknowledgements}

We acknowledge the commitment of the staff of the Department of Diagnostic Pathology and of the Department of Surgery, Kuma Hospital, Kobe, Japan; the staff of the Laboratory of Morphology of Endocrine System and of the Department of Surgery of Endocrine System of IEM, who prepared all pathological material and operated the patients, respectively. The authors gratefully acknowledge the confirmation of Ukrainian diagnoses provided by the International Pathology Panel of the Chernobyl Tissue Bank: Professors A. Abrosimov, T. Bogdanova, G. Fadda, J. Hunt, M. Ito, V. Livolsi, J. Rosai, E.D. Williams, and Dr. N. Dvinskyh. This work was supported in part by JSPS KAKENHI Grant Number 16H02774.

\section{Disclosure}

The authors declare that there is no conflict of interest that could be perceived as prejudicing the impartiality of the research reported. 
Supplementary Table 1 Comparative characteristics of the Japanese and Ukrainian pediatric sporadic papillary thyroid carcinoma for all, fully encapsulated and non-encapsulated tumors

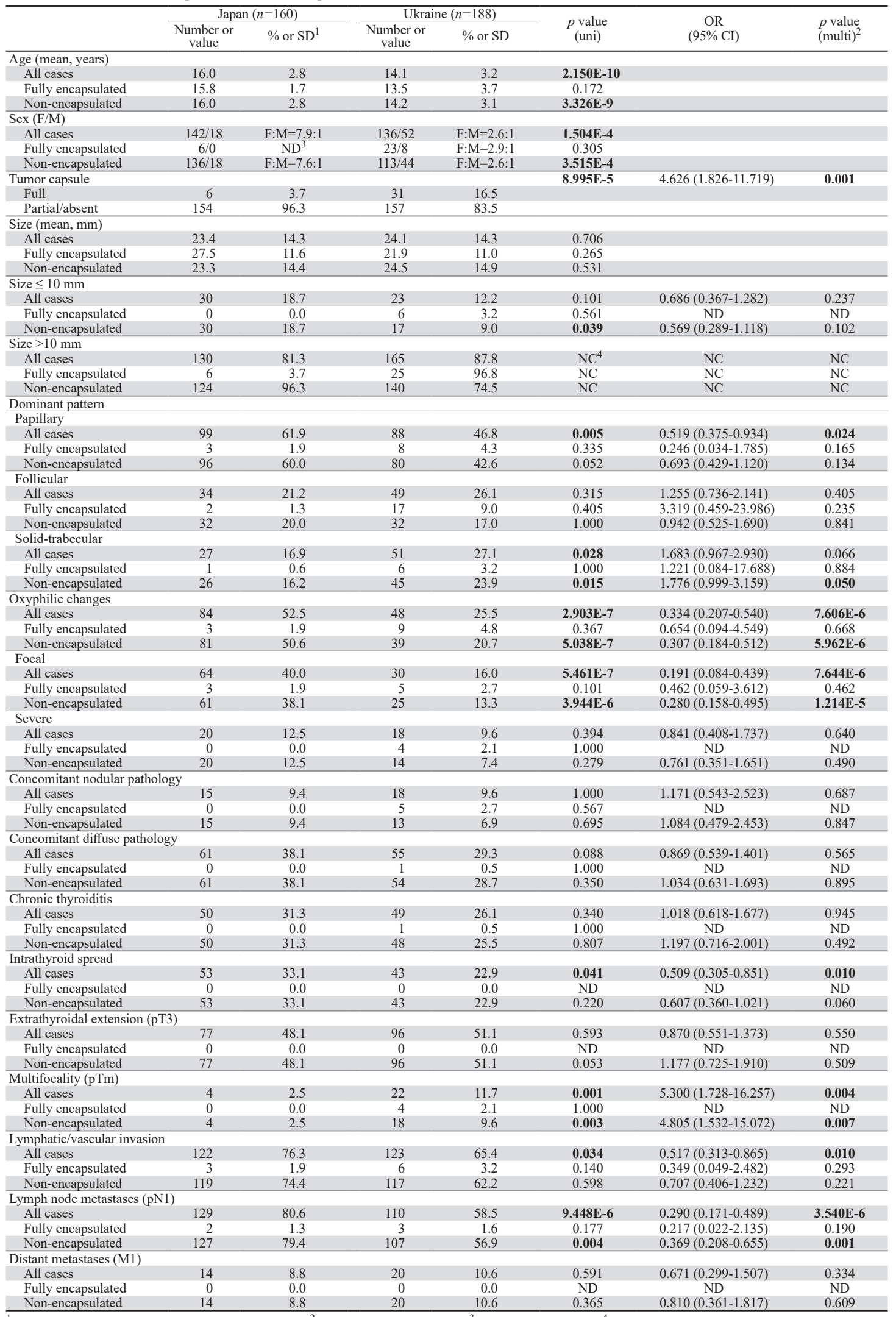

$1 \%$ for count data, SD for continuous numeric data. ${ }^{2}$ Adjusted for age and sex. ${ }^{3} \mathrm{ND}$, not determined. ${ }^{4} \mathrm{NC}$, not calculated due to data complementarity to size $\leq 10 \mathrm{~mm}$. 
Supplementary Table 2 Comparative characteristics of the Japanese and Ukrainian sporadic papillary thyroid carcinoma with the dominant papillary growth pattern in the combined pediatric groups

\begin{tabular}{|c|c|c|c|c|c|c|c|}
\hline & \multicolumn{2}{|c|}{ Japan $(n=99)$} & \multicolumn{2}{|c|}{ Ukraine $(n=88)$} & \multirow[b]{2}{*}{$\begin{array}{c}p \text { value } \\
\text { (uni) }\end{array}$} & \multirow[b]{2}{*}{$\begin{array}{c}\text { OR } \\
(95 \% \mathrm{CI})\end{array}$} & \multirow[b]{2}{*}{$\begin{array}{l}p \text { value } \\
(\text { multi) }\end{array}$} \\
\hline & $\begin{array}{l}\text { Number or } \\
\text { value }\end{array}$ & $\%$ or $\mathrm{SD}^{1}$ & $\begin{array}{l}\text { Number or } \\
\text { value }\end{array}$ & $\%$ or SD & & & \\
\hline \multicolumn{8}{|l|}{ Age (mean, years) } \\
\hline All cases & 16.4 & 2.5 & 14.3 & 3.2 & $3.882 \mathrm{E}-8$ & & \\
\hline Fully encapsulated & 16.1 & 1.3 & 13.5 & 3.9 & 0.220 & & \\
\hline Non-encapsulated & 16.4 & 2.5 & 14.3 & 3.2 & $1.263 \mathrm{E}-7$ & & \\
\hline \multicolumn{8}{|l|}{$\operatorname{Sex}(\mathrm{F} / \mathrm{M})$} \\
\hline All cases & $85 / 14$ & $\mathrm{~F}: \mathrm{M}=6.1: 1$ & $63 / 25$ & $\mathrm{~F}: \mathrm{M}=2.5: 1$ & 0.019 & & \\
\hline Fully encapsulated & $3 / 0$ & $\mathrm{ND}^{3}$ & $4 / 4$ & $\mathrm{~F}: \mathrm{M}=1.0: 1$ & 0.236 & & \\
\hline Non-encapsulated & $82 / 14$ & $\mathrm{~F}: \mathrm{M}=5.9: 1$ & $59 / 21$ & $\mathrm{~F}: \mathrm{M}=2.8: 1$ & 0.060 & & \\
\hline Tumor capsule & & & & & 0.118 & $2.896(0.729-11.513)$ & 0.131 \\
\hline Full & 3 & 3.0 & 8 & 9.1 & & & \\
\hline Partial/absent & 96 & 96.3 & 80 & 90.9 & & & \\
\hline \multicolumn{8}{|l|}{ Size (mean, $\mathrm{mm}$ ) } \\
\hline All cases & 22.4 & 13.4 & 23.3 & 15.1 & 0.954 & & \\
\hline Fully encapsulated & 33.7 & 8.3 & 18.5 & 10.7 & 0.133 & & \\
\hline Non-encapsulated & 22.0 & 13.4 & 23.7 & 15.4 & 0.742 & & \\
\hline \multicolumn{8}{|l|}{ Size $\leq 10 \mathrm{~mm}$} \\
\hline All cases & 20 & 20.2 & 13 & 14.8 & 0.354 & $0.650(0.297-1.422)$ & 0.281 \\
\hline Fully encapsulated & 0 & 0.0 & 2 & 2.3 & 1.000 & ND & ND \\
\hline Non-encapsulated & 20 & 20.2 & 11 & 12.5 & 0.239 & $0.583(0.258-1.319)$ & 0.196 \\
\hline Size $>10 \mathrm{~mm}$ & & & & & & & \\
\hline All cases & 79 & 79.8 & 75 & 85.2 & $\mathrm{NC}^{4}$ & $\mathrm{NC}$ & $\mathrm{NC}$ \\
\hline Fully encapsulated & 3 & 3.0 & 6 & 6.8 & $\mathrm{NC}$ & $\mathrm{NC}$ & $\mathrm{NC}$ \\
\hline Non-encapsulated & 76 & 76.8 & 69 & 78.4 & $\mathrm{NC}$ & $\mathrm{NC}$ & $\mathrm{NC}$ \\
\hline Oxyphilic changes & & & & & & & \\
\hline All cases & 63 & 63.6 & 21 & 23.9 & 4.223E-8 & $0.204(0.104-0.401)$ & $4.020 \mathrm{E}-6^{5}$ \\
\hline Fully encapsulated & 1 & 1.0 & 2 & 2.3 & 1.000 & $2.000(0.090-44.350)$ & 0.661 \\
\hline Non-encapsulated & 62 & 62.6 & 19 & 21.6 & $7.156 \mathrm{E}-8$ & $0.189(0.094-0.382)$ & $3.317 \mathrm{E}-6^{5}$ \\
\hline Focal & & & & & & & \\
\hline All cases & 49 & 49.5 & 17 & 19.3 & $1.637 \mathrm{E}-5$ & $0.248(0.122-0.505)$ & $1.176 \mathrm{E}-4^{5}$ \\
\hline Fully encapsulated & 1 & 1.0 & 2 & 2.3 & 1.000 & $2.000(0.090-44.350)$ & 0.661 \\
\hline Non-encapsulated & 48 & 48.5 & 15 & 17.0 & $1.745 \mathrm{E}-5$ & $0.228(0.109-0.479)$ & $9.331 \mathrm{E}-5^{5}$ \\
\hline Severe & & & & & & & \\
\hline All cases & 14 & 14.1 & 4 & 4.5 & 0.044 & $0.384(0.111-1.328)$ & $0.130^{5}$ \\
\hline Fully encapsulated & 0 & 0.0 & 0 & 0.0 & ND & ND & ND \\
\hline Non-encapsulated & 14 & 14.1 & 4 & 4.5 & 0.046 & $0.398(0.116-1.372)$ & $0.145^{5}$ \\
\hline Concomitant nodular $\mathrm{p}$ & & & & & & & \\
\hline All cases & 9 & 9.1 & 9 & 10.2 & 0.809 & $1.129(0.420-3.031)$ & 0.810 \\
\hline Fully encapsulated & 0 & 0.0 & 2 & 2.3 & 1.000 & ND & ND \\
\hline Non-encapsulated & 9 & 9.1 & 7 & 8.0 & 1.000 & $0.984(0.346-2.798)$ & 0.975 \\
\hline Concomitant diffuse pa & & & & & & & \\
\hline All cases & 43 & 43.4 & 29 & 33.3 & 0.176 & $0.734(0.397-1.357)$ & 0.324 \\
\hline Fully encapsulated & 0 & 0.0 & 1 & 1.1 & 1.000 & ND & ND \\
\hline Non-encapsulated & 43 & 43.4 & 28 & 31.8 & 0.218 & $0.738(0.395-1.382)$ & 0.343 \\
\hline Chronic thyroiditis & & & & & & & \\
\hline All cases & 37 & 37.4 & 26 & 29.5 & 0.281 & $0.821(0.436-1.547)$ & 0.542 \\
\hline Fully encapsulated & 0 & 0.0 & 1 & 1.1 & 1.000 & ND & ND \\
\hline Non-encapsulated & 37 & 37.4 & 25 & 28.4 & 0.344 & $0.819(0.430-1.561)$ & 0.544 \\
\hline Intrathyroid spread & & & & & & & \\
\hline All cases & 35 & 35.4 & 21 & 23.9 & 0.110 & $0.585(0.306-1.121)$ & 0.106 \\
\hline Fully encapsulated & 0 & 0.0 & 0 & 0.0 & ND & ND & ND \\
\hline Non-encapsulated & 35 & 35.4 & 21 & 23.9 & 0.193 & $0.628(0.326-1.209)$ & 0.164 \\
\hline Extrathyroidal extensic & & & & & & & \\
\hline All cases & 42 & 42.4 & 42 & 47.7 & 0.556 & $1.236(0.687-2.223)$ & 0.479 \\
\hline Fully encapsulated & 0 & 0.0 & 0 & 0.0 & ND & ND & ND \\
\hline Non-encapsulated & 42 & 42.4 & 42 & 47.7 & 0.289 & $1.401(0.767-2.558)$ & 0.273 \\
\hline Multifocality (pTm) & & & & & & & \\
\hline All cases & 3 & 3.0 & 10 & 11.4 & 0.041 & $4.470(1.174-17.017)$ & 0.028 \\
\hline Fully encapsulated & 0 & 0.0 & 1 & 1.1 & 1.000 & ND & ND \\
\hline Non-encapsulated & 3 & 3.0 & 9 & 10.2 & 0.039 & $4.132(1.068-15.982)$ & 0.040 \\
\hline Lymphatic/vascular in & & & & & & & \\
\hline All cases & 75 & 75.8 & 54 & 61.4 & 0.040 & $0.519(0.274-0.982)$ & 0.044 \\
\hline Fully encapsulated & 3 & 3.0 & 0 & 0.0 & 0.006 & ND & ND \\
\hline Non-encapsulated & 72 & 72.7 & 54 & 61.4 & 0.315 & $0.688(0.354-1.337)$ & 0.269 \\
\hline Lymph node metastase & & & & & & & \\
\hline All cases & 85 & 85.9 & 58 & 65.9 & 0.002 & $0.336(0.156-0.725)^{5}$ & $0.005^{5}$ \\
\hline Fully encapsulated & 2 & 2.0 & 2 & 2.3 & 0.491 & $0.500(0.0 .23-11.088)$ & 0.661 \\
\hline Non-encapsulated & 83 & 83.8 & 56 & 63.6 & 0.009 & $0.369(0.165-0.828)$ & $0.016^{5}$ \\
\hline Distant metastases (M) & & & & & & & \\
\hline All cases & 7 & 7.1 & 10 & 11.4 & 0.323 & $1.669(0.598-4.662)$ & 0.328 \\
\hline Fully encapsulated & 0 & 0.0 & 0 & 0.0 & ND & ND & ND \\
\hline Non-encapsulated & 7 & 7.1 & 10 & 11.4 & 0.308 & $1.787(0.640-4.985)$ & 0.268 \\
\hline
\end{tabular}

$1 \%$ for count data, SD for continuous numeric data. ${ }^{2}$ Adjusted for sex unless otherwise specified. ${ }^{3} \mathrm{ND}$, not determined. ${ }^{4} \mathrm{NC}$, not calculated due to data complementarity to size $\leq 10 \mathrm{~mm}$. ${ }^{5}$ Adjusted for age and sex. 
Supplementary Table 3 Comparative characteristics of the Japanese and Ukrainian sporadic papillary thyroid carcinoma with the dominantsolid-trabecular growth pattern in the combined pediatric groups

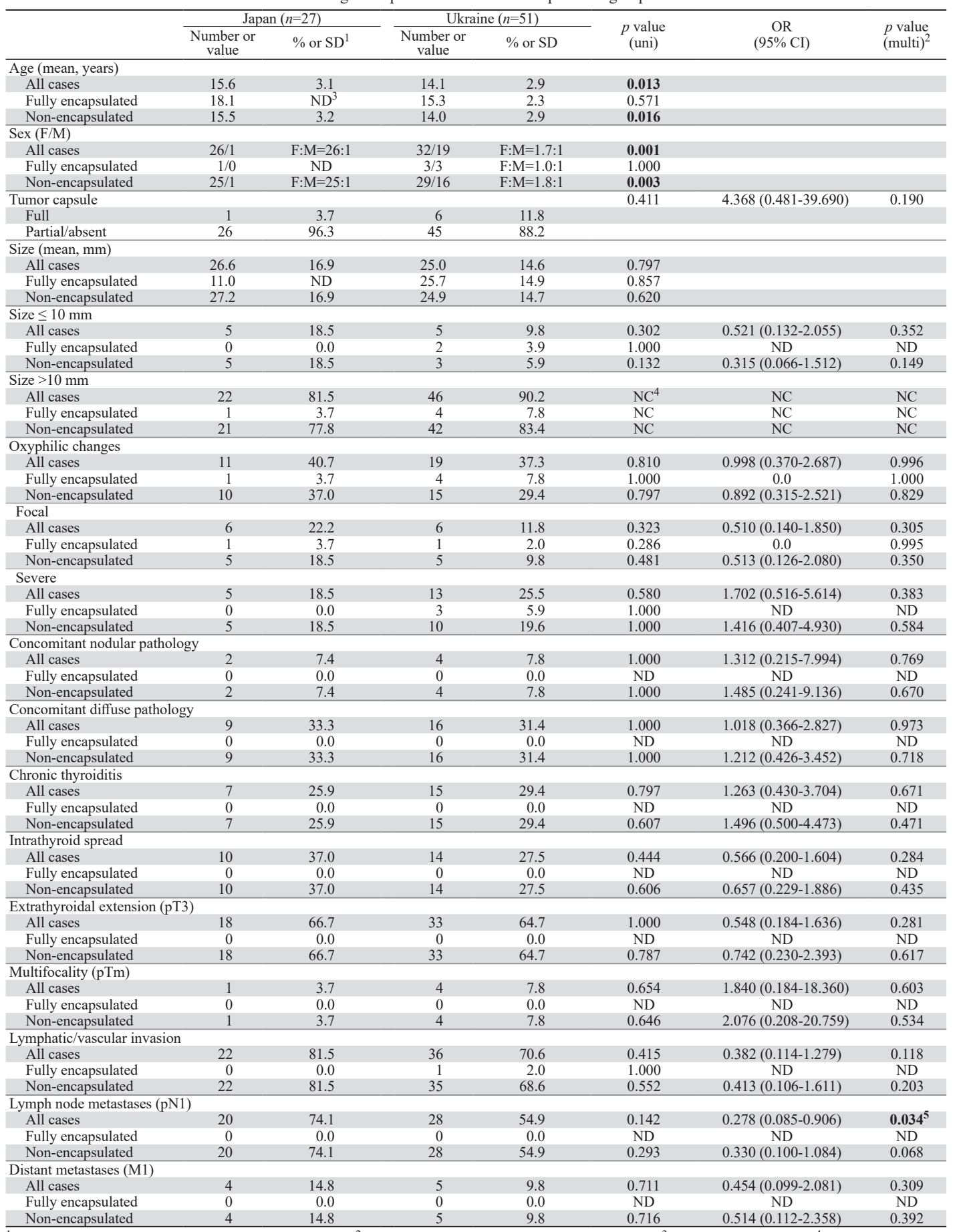

$1 \%$ for count data, SD for continuous numeric data. ${ }^{2}$ Adjusted for age unless otherwise specified. ${ }^{3} \mathrm{ND}$, not determined. ${ }^{4} \mathrm{NC}$, not calculated due to data complementarity to size $\leq 10 \mathrm{~mm} .{ }^{5}$ Adjusted for age and sex. 
Supplementary Table 4 Associations of demographic and histopathological characteristics with the dominant growth pattern in the combined pediatric group from Japan

\begin{tabular}{|c|c|c|c|c|c|c|c|c|c|}
\hline & \multicolumn{2}{|c|}{ Papillary $(n=99)$} & \multicolumn{2}{|c|}{ Follicular $(n=34)$} & \multicolumn{2}{|c|}{ Solid-trabecular $(n=27)$} & \multirow{2}{*}{$\begin{array}{l}p \text { value } \\
\text { (uni) }^{2}\end{array}$} & \multirow{2}{*}{$\begin{array}{c}\text { OR } \\
(95 \% \mathrm{CI})\end{array}$} & \multirow{2}{*}{$\begin{array}{l}p \text { value } \\
\text { (multi) }\end{array}$} \\
\hline & $\begin{array}{c}\text { Number or } \\
\text { value }\end{array}$ & $\%$ or $\mathrm{SD}^{1}$ & $\begin{array}{c}\text { Number or } \\
\text { value }\end{array}$ & $\%$ or SD & $\begin{array}{c}\text { Number or } \\
\text { value }\end{array}$ & $\%$ or SD & & & \\
\hline Age (mean, years) & & & & & & & & & \\
\hline All cases & 16.4 & 2.5 & 15.3 & 3.1 & 15.6 & 3.1 & 0.096 & & \\
\hline Fully encapsulated & 16.1 & 1.3 & 14.3 & 0.9 & 18.1 & $\mathrm{ND}^{4}$ & 0.117 & & \\
\hline Non-encapsulated & 16.4 & 2.5 & 15.3 & 3.2 & 15.5 & 3.2 & & 0.118 & \\
\hline $\operatorname{Sex}(\mathrm{F} / \mathrm{M})$ & & & & & & & & & \\
\hline All cases & $85 / 14$ & $\mathrm{~F}: \mathrm{M}=6.1: 1$ & $31 / 3$ & $\mathrm{~F}: \mathrm{M}=10.3: 1$ & $26 / 1$ & $\mathrm{~F}: \mathrm{M}=26.0: 1$ & 0.304 & & \\
\hline Fully encapsulated & $3 / 0$ & ND & $2 / 0$ & ND & $1 / 0$ & ND & 1.000 & & \\
\hline Non-encapsulated & $82 / 14$ & $\mathrm{~F}: \mathrm{M}=5.9: 1$ & $29 / 3$ & $\mathrm{~F}: \mathrm{M}=9.7: 1$ & $25 / 1$ & $\mathrm{~F}: \mathrm{M}=25.0: 1$ & 0.348 & & \\
\hline Tumor capsule & & & & & & & 0.722 & & $\mathrm{NS}^{5}$ \\
\hline Full & 3 & 3.0 & 2 & 5.9 & 1 & 3.7 & & & \\
\hline Partial/absent & 96 & 97.0 & 32 & 94.1 & 26 & 96.3 & & & \\
\hline Size (mean, mm) & & & & & & & & & \\
\hline All cases & 22.4 & 13.4 & 23.9 & 14.6 & 26.6 & 16.9 & 0.556 & & \\
\hline Fully encapsulated & 33.7 & 8.3 & 26.5 & 12.0 & 11.0 & ND & 0.304 & & \\
\hline Non-encapsulated & 22.0 & 13.4 & 23.7 & 14.9 & 27.2 & 16.9 & 0.393 & & \\
\hline Size $\leq 10 \mathrm{~mm}$ & & & & & & & & & \\
\hline All cases & 20 & 20.2 & 5 & 14.7 & 5 & 18.5 & 0.808 & & NS \\
\hline Fully encapsulated & 0 & 0.0 & 0 & 0.0 & 0 & 0.0 & 1.000 & & ND \\
\hline Non-encapsulated & 20 & 20.2 & 5 & 14.7 & 5 & 18.5 & 0.880 & & NS \\
\hline Size $>10 \mathrm{~mm}$ & & & & & & & & & \\
\hline All cases & 79 & 79.8 & 29 & 85.3 & 22 & 81.5 & $\mathrm{NC}^{6}$ & $\mathrm{NC}$ & $\mathrm{NC}$ \\
\hline Fully encapsulated & 3 & 3.0 & 2 & 5.9 & 1 & 3.7 & $\mathrm{NC}$ & $\mathrm{NC}$ & $\mathrm{NC}$ \\
\hline Non-encapsulated & 76 & 76.8 & 27 & 79.4 & 21 & 77.8 & $\mathrm{NC}$ & $\mathrm{NC}$ & $\mathrm{NC}$ \\
\hline Oxyphilic changes & & & & & & & & & \\
\hline All cases & 63 & 63.6 & 10 & 29.4 & 11 & 40.7 & 0.001 & $4.166(1.778-9.762)$ & $0.001^{7}$ \\
\hline All cases & & & & & & & & $2.488(1.034-5.988)$ & $0.042^{8}$ \\
\hline Fully encapsulated & 1 & 1.0 & 1 & 2.9 & 1 & 3.7 & 0.700 & & NS \\
\hline Non-encapsulated & 62 & 62.6 & 9 & 26.5 & 10 & 37.0 & $4.756 \mathrm{E}-4$ & $4.562(1.925-11.242)$ & $0.001^{7}$ \\
\hline Non-encapsulated & & & & & & & & $2.869(1.162-7.085)$ & $0.022^{8}$ \\
\hline Focal & & & & & & & & & \\
\hline All cases & 49 & 49.5 & 9 & 26.5 & 6 & 22.2 & 0.007 & $2.659(1.117-6.328)$ & $0.027^{7}$ \\
\hline All cases & & & & & & & & $3.253(1.200-8.816)$ & $0.020^{8}$ \\
\hline Fully encapsulated & 1 & 1.0 & 1 & 2.9 & 1 & 3.7 & 0.700 & & NS \\
\hline Non-encapsulated & 48 & 48.5 & 8 & 23.5 & 5 & 18.5 & 0.002 & $2.948(1.197-7.263)$ & $0.019^{7}$ \\
\hline Non-encapsulated & & & & & & & & $3.999(1.381-11.582)$ & $0.011^{8}$ \\
\hline Severe & & & & & & & & & \\
\hline All cases & 14 & 14.1 & 1 & 2.9 & 5 & 18.5 & 0.121 & & NS \\
\hline Fully encapsulated & 0 & 0.0 & 0 & 0.0 & 0 & 0.0 & 1.000 & & ND \\
\hline Non-encapsulated & 14 & 14.1 & 1 & 2.9 & 5 & 18.5 & 0.118 & & NS \\
\hline Concomitant nodular $\mathrm{p}$ & & & & & & & & & \\
\hline All cases & 9 & 9.1 & 4 & 11.8 & 2 & 7.4 & 0.859 & & NS \\
\hline Fully encapsulated & 0 & 0.0 & 0 & 0.0 & 0 & 0.0 & 1.000 & & ND \\
\hline Non-encapsulated & 9 & 9.1 & 4 & 11.8 & 2 & 7.4 & 0.858 & & NS \\
\hline Concomitant diffuse $\mathrm{p}$ & & & & & & & & & \\
\hline All cases & 43 & 43.4 & 9 & 26.5 & 9 & 33.3 & 0.184 & & NS \\
\hline Fully encapsulated & 0 & 0.0 & 0 & 0.0 & 0 & 0.0 & 1.000 & & ND \\
\hline Non-encapsulated & 43 & 43.4 & 9 & 26.5 & 9 & 33.3 & 0.229 & & NS \\
\hline Chronic thyroiditis & & & & & & & & & \\
\hline All cases & 37 & 37.4 & 6 & 17.6 & 7 & 25.9 & 0.091 & $2.956(1.103-7.923)$ & $0.031^{7}$ \\
\hline Fully encapsulated & 0 & 0.0 & 0 & 0.0 & 0 & 0.0 & 1.000 & & ND \\
\hline Non-encapsulated & 37 & 37.4 & 6 & 17.6 & 7 & 25.9 & 0.098 & $2.932(1.087-7.912)$ & $0.034^{7}$ \\
\hline Intrathyroid spread & & & & & & & & & \\
\hline All cases & 35 & 35.3 & 8 & 23.5 & 10 & 37.0 & 0.448 & & NS \\
\hline Fully encapsulated & 0 & 0.0 & 0 & 0.0 & 0 & 0.0 & 1.000 & & ND \\
\hline Non-encapsulated & 35 & 35.3 & 8 & 23.5 & 10 & 37.0 & 0.480 & & NS \\
\hline Extrathyroidal extensi & & & & & & & & & \\
\hline All cases & 42 & 42.4 & 17 & 50.0 & 18 & 66.7 & 0.075 & $0.349(0.139-0.871)$ & $0.024^{8}$ \\
\hline Fully encapsulated & 0 & 0.0 & 0 & 0.0 & 0 & 0.0 & 1.000 & & ND \\
\hline Non-encapsulated & 42 & 42.4 & 17 & 50.0 & 18 & 66.7 & 0.069 & $0.335(0.129-0.867)$ & $0.024^{8}$ \\
\hline Multifocality (pTm) & & & & & & & & & \\
\hline All cases & 3 & 3.0 & 0 & 0.0 & 1 & 3.7 & 0.628 & & NS \\
\hline Fully encapsulated & 0 & 0.0 & 0 & 0.0 & 0 & 0.0 & 1.000 & & ND \\
\hline Non-encapsulated & 3 & 3.0 & 0 & 0.0 & 1 & 3.7 & 0.629 & & ND \\
\hline Lymphatic/vascular in & & & & & & & & & \\
\hline All cases & 75 & 75.8 & 25 & 73.5 & 22 & 81.5 & 0.804 & & NS \\
\hline Fully encapsulated & 3 & 3.0 & 0 & 0.0 & 0 & 0.0 & 0.050 & & NS \\
\hline Non-encapsulated & 72 & 72.7 & 25 & 73.5 & 22 & 81.5 & 0.626 & & NS \\
\hline Lymph node metastase & & & & & & & & & \\
\hline All cases & 85 & 85.6 & 24 & 70.6 & 20 & 74.1 & 0.085 & $2.656(1.035-6.813)$ & $0.042^{7}$ \\
\hline Fully encapsulated & 2 & 2.0 & 0 & 0.0 & 0 & 0.0 & 0.400 & & NS \\
\hline Non-encapsulated & 83 & 83.8 & 24 & 70.6 & 20 & 74.1 & 0.215 & & NS \\
\hline Distant metastases (M & & & & & & & & & \\
\hline All cases & 7 & 7.1 & 3 & 8.8 & 4 & 14.8 & 0.443 & & NS \\
\hline Fully encapsulated & 0 & 0.0 & 0 & 0.0 & 0 & 0.0 & 1.000 & & ND \\
\hline Non-encapsulated & 7 & 7.1 & 3 & 8.8 & 4 & 14.8 & 0.370 & & NS \\
\hline
\end{tabular}

${ }^{1} \%$ for count data, SD for continuous numeric data. ${ }^{2}$ Kruskal-Wallis or $2 \times 3$ Fisher's exact test for continuous or count data, respectively. ${ }^{3}$ Multinomial logistic regression. Adjusted for age and sex; only the results with significant $p$-values are shown. ${ }^{4} \mathrm{ND}$, not determined. ${ }^{5} \mathrm{NS}$, not significant for any growth pattern. ${ }^{6} \mathrm{NC}$, not calculated due to data complementarity to size $\leq 10 \mathrm{~mm} .{ }^{7}$ Dominant papillary $v s$. dominant follicular growth pattern. ${ }^{8}$ Dominant papillary $v s$. dominant solid-trabecular growth pattern. 
Supplementary Table 5 Associations of demographic and histopathological characteristics with the dominant growth pattern in the combined pediatric group from Ukraine

\begin{tabular}{|c|c|c|c|c|c|c|c|c|c|}
\hline & \multicolumn{2}{|c|}{ Papillary $(n=88)$} & \multicolumn{2}{|c|}{ Follicular $(n=49)$} & \multicolumn{2}{|c|}{ Solid-trabecular $(n=51)$} & \multirow{2}{*}{$\begin{array}{c}p \text { value } \\
(\text { uni })^{2}\end{array}$} & \multirow{2}{*}{$\begin{array}{c}\text { OR } \\
(95 \% \mathrm{CI})\end{array}$} & \multirow{2}{*}{$\begin{array}{l}p \text { value } \\
\text { (multi) }^{3}\end{array}$} \\
\hline & $\begin{array}{c}\text { Number or } \\
\text { value }\end{array}$ & $\%$ or $\mathrm{SD}^{1}$ & $\begin{array}{c}\text { Number or } \\
\text { value }\end{array}$ & $\%$ or SD & $\begin{array}{c}\text { Number or } \\
\text { value }\end{array}$ & $\%$ or SD & & & \\
\hline Age (mean, years) & & & & & & & & & \\
\hline All cases & 14.3 & 3.2 & 13.8 & 3.6 & 14.1 & 2.9 & 0.096 & & \\
\hline Fully encapsulated & 13.5 & 3.9 & 12.9 & 3.9 & 15.3 & 2.3 & 0.117 & & \\
\hline Non-encapsulated & 14.3 & 3.2 & 14.3 & 3.4 & 14.0 & 2.9 & & 0.570 & \\
\hline $\operatorname{Sex}(F / M)$ & & & & & & & & & \\
\hline All cases & $63 / 25$ & $\mathrm{~F}: \mathrm{M}=2.5: 1$ & $41 / 8$ & $\mathrm{~F}: \mathrm{M}=5.1: 1$ & $32 / 19$ & $\mathrm{~F}: \mathrm{M}=1.7: 1$ & 0.061 & & \\
\hline Fully encapsulated & $4 / 4$ & $\mathrm{~F}: \mathrm{M}=1.0: 1$ & $16 / 1$ & $\mathrm{~F}: \mathrm{M}=16.0: 1$ & $3 / 3$ & $\mathrm{~F}: \mathrm{M}=1.0: 1$ & 0.013 & & \\
\hline Non-encapsulated & $59 / 21$ & $\mathrm{~F}: \mathrm{M}=2.8: 1$ & $25 / 7$ & $\mathrm{~F}: \mathrm{M}=3.6: 1$ & $29 / 16$ & $\mathrm{~F}: \mathrm{M}=1.8: 1$ & 0.388 & & \\
\hline Tumor capsule & & & & & & & $<0.0001$ & $5.469(2.114-14.147)$ & $4.581 \mathrm{E}-4^{4}$ \\
\hline & & & & & & & & $4.301(1.484-12.462)$ & $0.007^{5}$ \\
\hline Full & 8 & 9.1 & 17 & 34.7 & 6 & 11.8 & & $\mathrm{NC}^{6}$ & $\mathrm{NC}$ \\
\hline Partial/absent & 80 & 90.9 & 32 & 65.3 & 45 & 88.2 & & $\mathrm{NC}$ & $\mathrm{NC}$ \\
\hline Size (mean, mm) & & & & & & & & & \\
\hline All cases & 23.3 & 15.1 & 24.6 & 12.7 & 25.0 & 14.6 & 0.556 & & \\
\hline Fully encapsulated & 18.5 & 10.7 & 22.1 & 9.8 & 25.7 & 14.9 & 0.304 & & \\
\hline Non-encapsulated & 23.7 & 15.4 & 25.9 & 13.9 & 24.9 & 14.7 & 0.468 & & \\
\hline Size $\leq 10 \mathrm{~mm}$ & & & & & & & & & \\
\hline All cases & 13 & 14.8 & 5 & 10.2 & 5 & 9.8 & 0.711 & & $\mathrm{NS}^{7}$ \\
\hline Fully encapsulated & 2 & 2.3 & 2 & 4.1 & 2 & 3.9 & 0.566 & & NS \\
\hline Non-encapsulated & 11 & 12.5 & 3 & 6.1 & 3 & 5.9 & 0.492 & & NS \\
\hline Size $>10 \mathrm{~mm}$ & & & & & & & & & \\
\hline All cases & 75 & 85.2 & 44 & 89.8 & 46 & 90.2 & $\mathrm{NC}$ & $\mathrm{NC}$ & $\mathrm{NC}$ \\
\hline Fully encapsulated & 6 & 6.8 & 15 & 30.6 & 4 & 7.8 & $\mathrm{NC}$ & $\mathrm{NC}$ & $\mathrm{NC}$ \\
\hline Non-encapsulated & 69 & 87.5 & 29 & 59.2 & 42 & 82.4 & $\mathrm{NC}$ & $\mathrm{NC}$ & $\mathrm{NC}$ \\
\hline Oxyphilic changes & & & & & & & & & \\
\hline All cases & 21 & 23.9 & 8 & 16.3 & 19 & 37.2 & 0.057 & $0.318(0.121-0.837)$ & $0.020^{5}$ \\
\hline Fully encapsulated & 2 & 2.3 & 3 & 6.1 & 4 & 7.8 & 0.124 & $0.041(0.002-0.715)$ & $0.028^{5}$ \\
\hline Non-encapsulated & 19 & 21.6 & 5 & 10.2 & 15 & 29.4 & 0.229 & & NS \\
\hline Focal & & & & & & & & & \\
\hline All cases & 17 & 19.3 & 7 & 14.3 & 6 & 11.8 & 0.504 & & NS \\
\hline Fully encapsulated & 2 & 2.3 & 2 & 4.1 & 1 & 2.0 & 0.942 & & NS \\
\hline Non-encapsulated & 15 & 17.0 & 5 & 10.2 & 5 & 9.8 & 0.574 & & NS \\
\hline Non-encapsulated & & & & & & & & & \\
\hline Severe & & & & & & & & & \\
\hline All cases & 4 & 4.5 & 1 & 2.0 & 13 & 25.5 & $<0.0001$ & $7.614(2.283-25.388)$ & $0.001^{8}$ \\
\hline All cases & & & & & & & & $0.060(0.007-0.491)$ & $0.009^{5}$ \\
\hline Fully encapsulated & 0 & 0.0 & 1 & 2.0 & 3 & 5.9 & 0.029 & & $\mathrm{ND}^{9}$ \\
\hline Non-encapsulated & 4 & 4.5 & 0 & 0.0 & 10 & 19.6 & 0.001 & & ND \\
\hline Concomitant nodular $\mathrm{p}$ & ogy & & & & & & & & \\
\hline All cases & 9 & 10.2 & 5 & 10.2 & 4 & 7.8 & 0.948 & & NS \\
\hline Fully encapsulated & 2 & 2.3 & 3 & 6.1 & 0 & 0.0 & 0.785 & & ND \\
\hline Non-encapsulated & 7 & 8.0 & 2 & 4.1 & 4 & 7.8 & 1.000 & & NS \\
\hline Concomitant diffuse pa & & & & & & & & & \\
\hline All cases & 29 & 33.0 & 10 & 20.4 & 16 & 31.4 & 0.287 & & NS \\
\hline Fully encapsulated & 1 & 1.1 & 0 & 0.0 & 0 & 0.0 & 0.710 & & ND \\
\hline Non-encapsulated & 28 & 31.8 & 10 & 20.4 & 16 & 31.4 & 0.950 & & NS \\
\hline Chronic thyroiditis & & & & & & & & & \\
\hline All cases & 26 & 29.5 & 8 & 16.3 & 15 & 29.4 & 0.190 & $0.396(0161-0.977)$ & $0.044^{4}$ \\
\hline All cases & & & & & & & & $0.355(0.131-0.967)$ & $0.043^{5}$ \\
\hline Fully encapsulated & 1 & 1.1 & 0 & 0.0 & 0 & 0.0 & 0.710 & & ND \\
\hline Non-encapsulated & 25 & 28.4 & 8 & 16.3 & 15 & 29.4 & 0.741 & & NS \\
\hline Intrathyroid spread & & & & & & & & & \\
\hline All cases & 21 & 23.9 & 8 & 16.3 & 14 & 27.5 & 0.391 & & NS \\
\hline Fully encapsulated & 0 & 0.0 & 0 & 0.0 & 0 & 0.0 & 1.000 & & ND \\
\hline Non-encapsulated & 21 & 23.9 & 8 & 16.3 & 14 & 27.5 & 0.391 & & NS \\
\hline Extrathyroidal extensio & & & & & & & & & \\
\hline All cases & 42 & 47.7 & 21 & 42.9 & 33 & 64.7 & 0.065 & $0.423(0.185-0.966)$ & $0.041^{5}$ \\
\hline Fully encapsulated & 0 & 0.0 & 0 & 0.0 & 0 & 0.0 & 1.000 & & ND \\
\hline Non-encapsulated & 42 & 47.7 & 21 & 42.9 & 33 & 64.7 & 0.065 & $2.297(1.011-5.219)$ & $0.047^{8}$ \\
\hline Multifocality (pTm) & & & & & & & & & \\
\hline All cases & 10 & 11.4 & 8 & 16.3 & 4 & 7.8 & 0.410 & & NS \\
\hline Fully encapsulated & 1 & 1.1 & 3 & 6.1 & 0 & 0.0 & 0.792 & & ND \\
\hline Non-encapsulated & 9 & 10.2 & 5 & 10.2 & 4 & 7.8 & 0.676 & & NS \\
\hline Lymphatic/vascular inv & & & & & & & & & \\
\hline All cases & 54 & 61.4 & 33 & 67.3 & 36 & 70.6 & 0.522 & & NS \\
\hline Fully encapsulated & 0 & 0.0 & 5 & 10.2 & 1 & 2.0 & 0.280 & & ND \\
\hline Non-encapsulated & 54 & 61.4 & 28 & 57.1 & 35 & 68.6 & 0.081 & $0.288(0.091-0.914)$ & $0.035^{4}$ \\
\hline Lymph node metastase & & & & & & & & & \\
\hline All cases & 58 & 65.9 & 24 & 49.0 & 28 & 54.9 & 0.130 & & NS \\
\hline Fully encapsulated & 2 & 2.3 & 1 & 2.0 & 0 & 0.0 & 0.349 & & ND \\
\hline Non-encapsulated & 56 & 63.6 & 23 & 47.0 & 28 & 54.9 & 0.589 & & NS \\
\hline Distant metastases (M & & & & & & & & & \\
\hline All cases & 10 & 11.4 & 5 & 10.2 & 5 & 9.8 & 1.000 & & NS \\
\hline Fully encapsulated & 0 & 0.0 & 0 & 0.0 & 0 & 0.0 & 1.000 & & ND \\
\hline Non-encapsulated & 10 & 11.4 & 5 & 10.2 & 5 & 9.8 & 1.000 & & NS \\
\hline
\end{tabular}

$1 \%$ for count data, SD for continuous numeric data. ${ }^{2}$ Kruskal-Wallis or $2 \times 3$ Fisher's exact test for continuous or count data, respectively. ${ }^{3}$ Multinomial logistic regression Adjusted for age and sex; only the results with significant $p$-values are shown. ${ }^{4}$ Dominant follicular $v s$. dominant papillary growth pattern. ${ }^{5}$ Dominant follicular $v s$. dominant solid-trabecular growth pattern. ${ }^{6} \mathrm{NC}$, not calculated due to data complementarity. ${ }^{7} \mathrm{NS}$, not significant for any growth pattern. ${ }^{8}$ Dominant solid-trabecular $v s$. dominant papillary growth pattern. ${ }^{9} \mathrm{ND}$, not determined. 
Supplementary Table 6 Comparative characteristics of the Japanese and Ukrainian sporadic papillary thyroid carcinoma for all, fully encapsulated and non-encapsulated tumors in children aged $\leq 14$ years at surgery

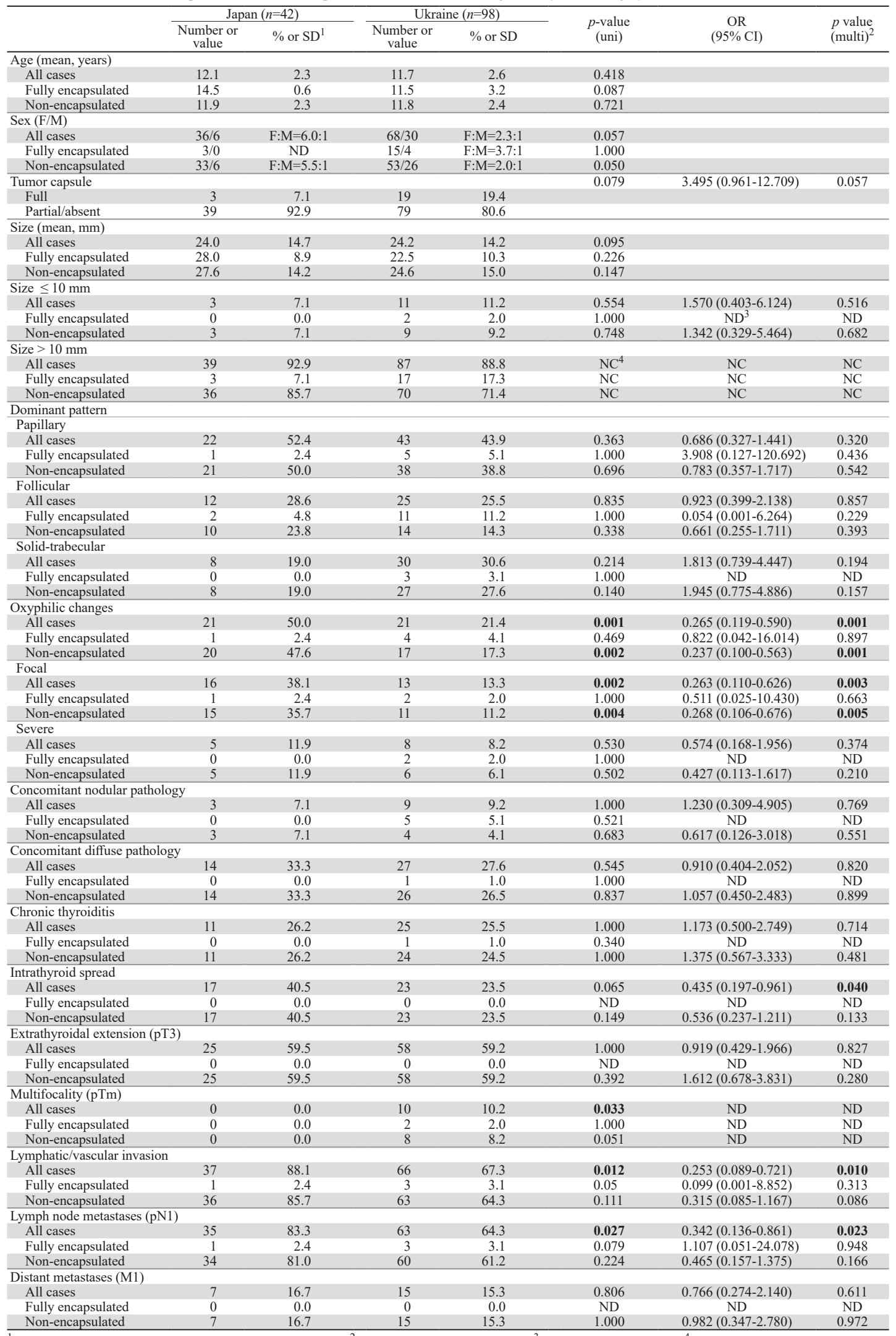

$1 \%$ for count data, SD for continuous numeric data. ${ }^{2}$ Adjusted for age and sex. ${ }^{3} \mathrm{ND}$, not determined. ${ }^{4}$ NC, not calculated due to data complementarity to size $\leq 10 \mathrm{~mm}$. 
Supplementary Table 7 Comparative characteristics of the Japanese and Ukrainian sporadic papillary thyroid carcinoma for all, fully encapsulated and non-encapsulated tumors in adolescents aged from 15 to $\leq 18$ years at surgery

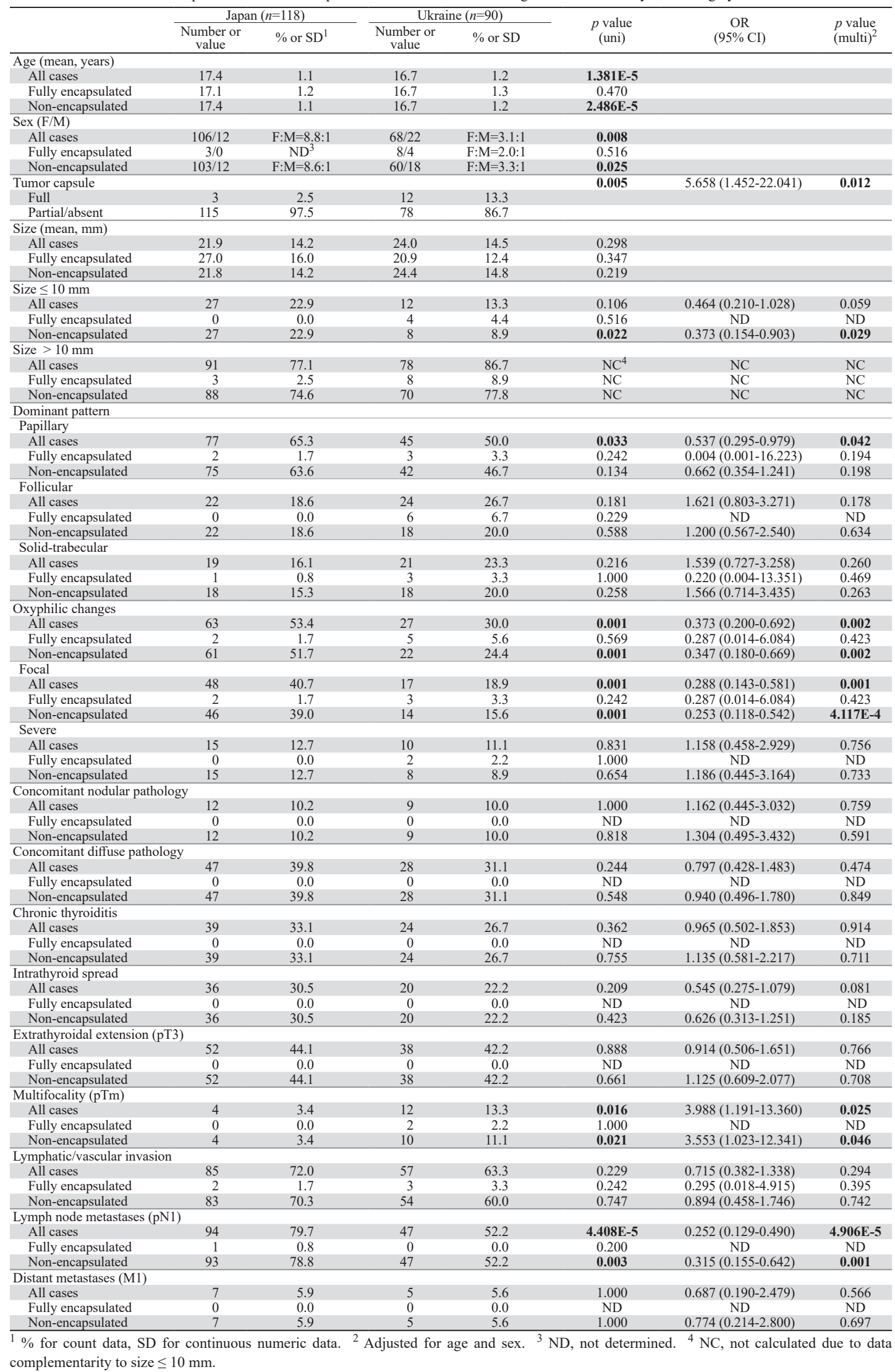


Supplementary Table 8 Comparison of childhood and adolescent PTC in the Japanese patients

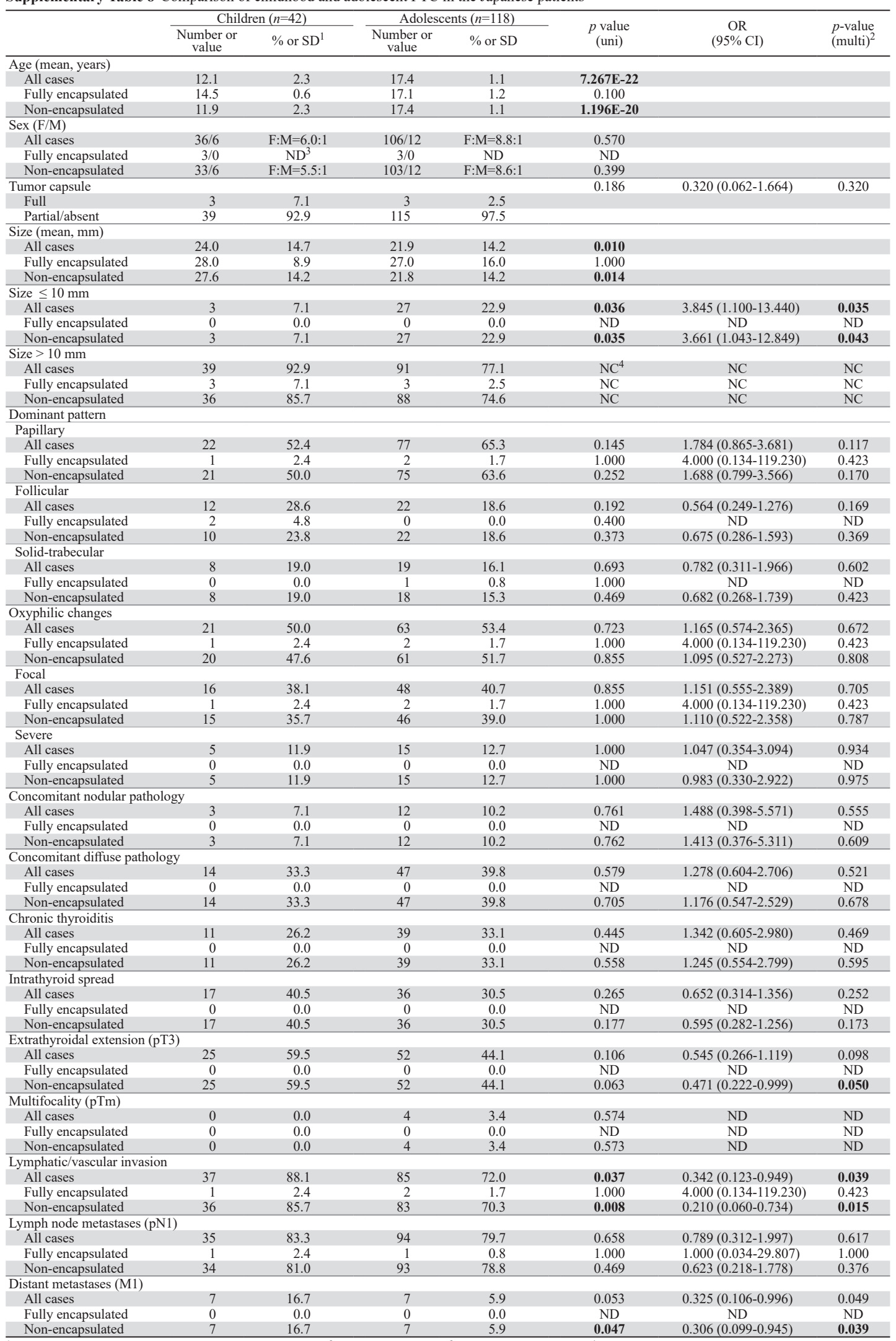

${ }_{1} \%$ for count data, SD for continuous numeric data. ${ }^{2}$ Adjusted for sex. ${ }^{3} \mathrm{ND}$, not determined. ${ }^{4} \mathrm{NC}$, not calculated due to data complementarity to size $\leq 10 \mathrm{~mm}$. 
Supplementary Table 9 Comparison of childhood and adolescent PTC in the Ukrainian patients

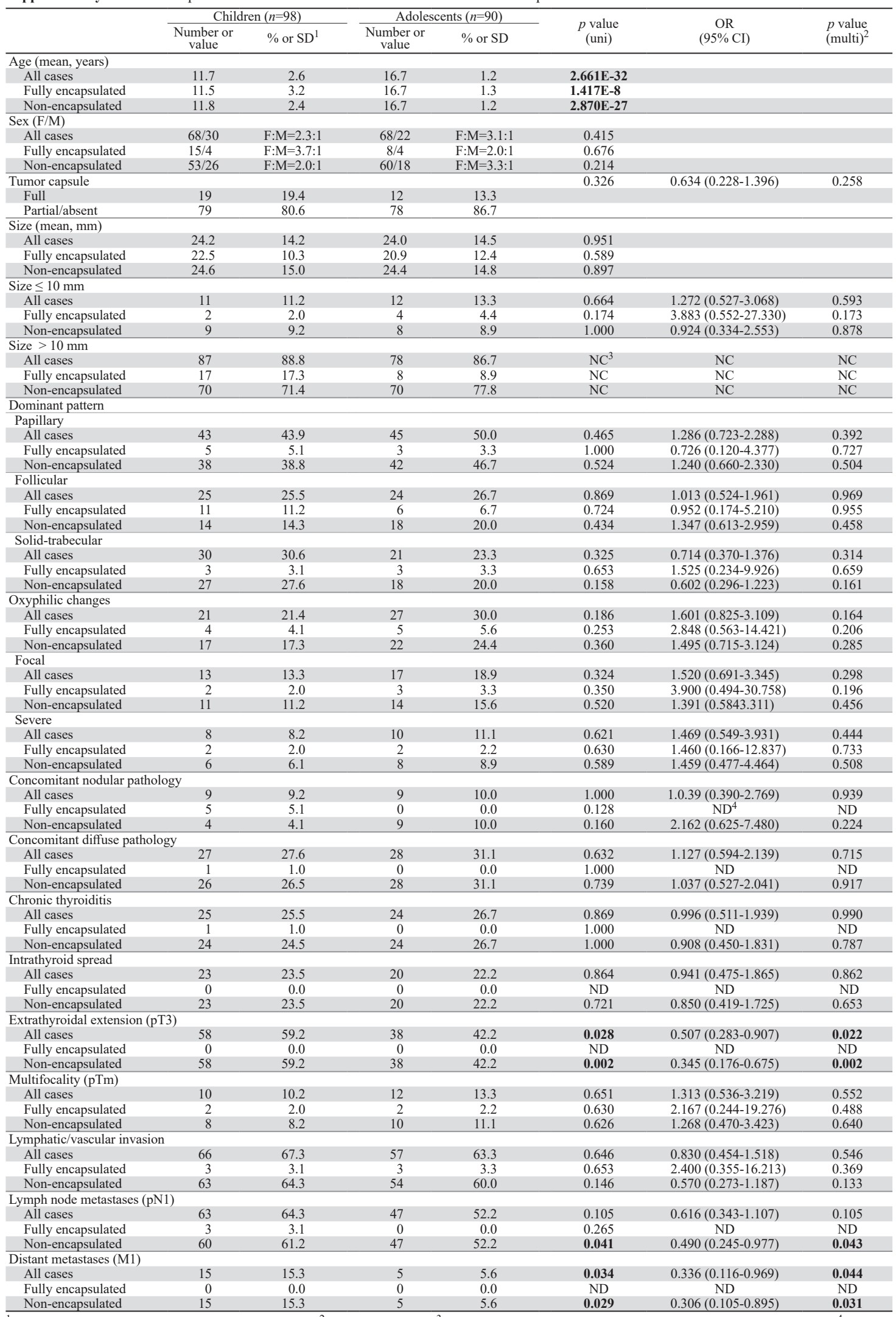

${ }^{1} \%$ for count data. SD for continuous numeric data. ${ }^{2}$ Adjusted for sex. ${ }^{3} \mathrm{NC}$, not calculated due to data complementarity to size $\leq 10 \mathrm{~mm} .{ }^{4} \mathrm{ND}$, not determined. 


\section{References}

1. Josefson J, Zimmerman D (2008) Thyroid nodules and cancers in children. Pediatr Endocrinol Rev 6: 14-23.

2. Center for Cancer Control and Information Services, National Cancer Center. Available from: http:/ganjoho.jp/en/professional/statistics/table_download.html. Accessed 2016 May 11.

3. Tronko M, Bodanova T, Shpak V, Gulak L (2016) Thyroid cancer in Ukraine during 1986-2014. In: Bazyka D, Sushko V, Chumak A, Chumak V, Yanovich L (eds) Health effects of Chornobyl accident thirty years aftermath. DIA, Kyiv: 85-103.

4. Ito M, Bogdanova $\mathrm{T}$, Zurnadzhy L, Saenko V, Rogounovitch T, et al. (2014) Morphological difference in adult thyroid papillary carcinoma between Japan and Ukraine. Endocr J 61: 1221-1228.

5. Shirahige Y, Ito M, Ashizawa K, Motomura T, Yokoyama $\mathrm{N}$, et al. (1998) Childhood thyroid cancer: comparison of Japan and Belarus. Endocr J 45: 203-209.

6. Williams ED, Abrosimov A, Bogdanova T, Demidchik EP, Ito M, et al. (2008) Morphologic characteristics of Chernobyl-related childhood papillary thyroid carcinomas are independent of radiation exposure but vary with iodine intake. Thyroid 18: 847-852.

7. DeLellis RA, Lloyd RV, Heitz PU, Eng C (eds) (2004) World Health Organization classification of tumors. Pathology and genetics of tumours of endocrine organs $\left(3^{\text {rd }}\right)$. IARC Press, Lyon.

8. Sobin LH, Gospodarowicz MK, Wittekind C, International Union against Cancer (2010) TNM classification of malignant tumours. Wiley-Blackwell, Chichester, UK.

9. Su HK, Wenig BM, Haser GC, Rowe ME, Asa SL, et al. (2016) Inter-observer variation in the pathologic identification of minimal extrathyroidal extension in papillary thyroid carcinoma. Thyroid 26: 512-517.

10. Bogdanova T, Zurnadzhy L, LiVolsi VA, Williams ED, Ito M, et al. (2014) Thyroid cancer pathology in Ukraine after Chernobyl. In: Tronko M, Bogdanova T, Saenko V, Thomas GA, Likhtarov I, Yamashita S (eds) Thyroid cancer in Ukraine after Chernobyl: dosimetry, epidemiology, pathology, molecular biology. IN-TEX, Nagasaki: 65-108.

11. Bogdanova T, Saenko V, Zurnadzhy L, Likhtarov I, Kovgan L, et al. (2014) Comparative pathological analysis of papillary thyroid carcinoma in age-matched groups of patients born before and after Chernobyl. In: Tronko M, Bogdanova T, Saenko V, Thomas GA, Likhtarov I, Yamashita S (eds) Thyroid cancer in Ukraine after Chernobyl: dosimetry, epidemiology, pathology, molecular biology. IN-TEX, Nagasaki: 109-134.

12. Fridman M, Lam AK, Krasko O, Schmid KW, Branovan DI, et al. (2015) Morphological and clinical presentation of papillary thyroid carcinoma in children and adolescents of Belarus: the influence of radiation exposure and the source of irradiation. Exp Mol Pathol 98: 527-531.

13. Oishi N, Kondo T, Nakazawa T, Mochizuki K, Inoue T, et al. (2017) Frequent BRAF V600E and absence of TERT promoter mutations characterize sporadic pediatric papillary thyroid carcinomas in Japan. Endocr Pathol 28: 103-111.

14. Bogdanova TI, Zurnadzhy LY, Nikiforov YE, LeemanNeill RJ, Tronko MD, et al. (2015) Histopathological features of papillary thyroid carcinomas detected during four screening examinations of a Ukrainian-American cohort. Br J Cancer 113: 1556-1564.

15. Ricarte-Filho JC, Li S, Garcia-Rendueles ME, MonteroConde C, Voza F, et al. (2013) Identification of kinase fusion oncogenes in post-Chernobyl radiation-induced thyroid cancers. J Clin Invest 123: 4935-4944.

16. Mitsutake N, Fukushima T, Matsuse M, Rogounovitch T, Saenko V, et al. (2015) BRAF(V600E) mutation is highly prevalent in thyroid carcinomas in the young population in Fukushima: a different oncogenic profile from Chernobyl. Sci Rep 5: 16976.

17. Enomoto Y, Enomoto K, Uchino S, Shibuya H, Watanabe S, et al. (2012) Clinical features, treatment, and long-term outcome of papillary thyroid cancer in children and adolescents without radiation exposure. World J Surg 36: 1241-1246. 